\title{
The Influence of Cigarette Moisture to the Chemistry of Particulate Phase Smoke of a Common Commercial Cigarette*
}

\author{
by \\ Q. Zha ${ }^{1,2}$ and S.C. Moldoveanu ${ }^{1}$ \\ ${ }^{1}$ R.J. Reynolds Tobacco Company, 950 Reynolds Boulevard, Winston-Salem, NC 27105, USA \\ ${ }^{2}$ Current Address: Celanese Acetate, 3520 Virginia Ave, Narrows, VA 24124, USA
}

\section{SUMMARY}

This study presents the results on the influence of cigarette moisture content to the chemical composition of particulate phase smoke. Seventy-five selected compounds were monitored for the comparison of particulate phase smoke of a commercial full-flavored (FF) cigarette with three different moisture contents at $7.8 \%, 14.5 \%$ and $20.4 \%$, respectively. It was demonstrated that the smoke of a dry cigarette is richer in lower molecular mass compounds than a regular cigarette. On the other hand, the smoke of a moist cigarette is richer in higher molecular mass compounds than a regular cigarette. To maximize the influence of cigarette moisture to the chemical composition, a separate set of measurements were done using only the first three puffs of smoke. The accumulation of moisture in the tobacco column of a burning cigarette may influence the smoke composition, as generated during burning. The differences between dry, regular and moist cigarettes were more obvious for the first three puffs. [Beitr. Tabakforsch. Int. 21 (2004) 184-191]

\section{ZUSAMMENFASSUNG}

Es werden die Ergebnisse einer Studie präsentiert, in der der Einfluss des Feuchtigkeitsgehalts einer Zigarette auf die chemische Zusammensetzung der Partikelphase des Zigarettenrauchs untersucht wurde. Hierzu wurden 75 ausgewählte Verbindungen in der Partikelphase des Rauchs einer handelsüblichen Full-Flavour Cigarette (FF) mit Feuchtigkeitsgehalten von 7,8\%, 14,5\% und $20 \%$ analysiert und die jeweiligen Partikelphasen wurden miteinander verglichen. Es wurde gezeigt, dass der Rauch einer trockenen Zigarette einen höheren Anteil an niedermolekularen Verbindungen enthält als eine Zigarette mit einem Feuchtigkeitsgehalt von $14,5 \%$. Andererseits sind im Rauch einer feuchten Zigarette mehr höhermolekulare Verbindungen enthalten als in einer Zigarette mit mittlerem Feuchtigkeitsgehalt. Um den Einfluss des Feuchtigkeitsgehalts einer Zigarette auf die chemische Zusammensetzung zu maximieren, wurden gesonderte Messungen durchgeführt, bei denen nur die ersten drei Züge untersucht wurden. Die Feuchtigkeitsansammlung im Tabakstrang einer brennenden Zigarette kann die während der Verbrennung generierte chemische Zusammensetzung des Rauches beeinflussen. Die Unterschiede zwischen einer trockenen, normalen und feuchten Zigarette waren während der ersten drei Züge an der Zigarette am deutlichsten. [Beitr. Tabakforsch. Int. 21 (2004) 184-191]

\section{RESUME}

Cette étude présente les résultats de l'influence du taux d'humidité des cigarettes sur la composition chimique de la phase particulaire de la fumée. 75 composants ont été dosés pour comparer la phase particulaire de la fumée d'une cigarette plein arôme dont les taux d'humidité étaient respectivement de $7,8 \%, 14,5 \%$ et $20,4 \%$. Il a été démontré que la fumée d'une cigarette sèche comporte davantage de composés à masse moléculaire plus faible que celle d'une cigarette standard à taux d'humidité de 14,5\%. En revanche, la fumée d'une cigarette humide comporte davantage de composés à masse moléculaire plus élevée que celle d'une cigarette standard. Pour maximiser l'influence du taux d'humidité des cigarettes sur la composition chimique, on a effectué une série de mesures en utilisant seulement les trois premières bouffées de la fumée. L'accumulation d'humidité dans la colonne de tabac d'une cigarette allumée peut avoir une influence sur la composition de la fumée générée au cours de la combustion. Les différences entre les cigarettes sèches, standard et humides étaient plus évidentes pendant les trois premières bouffées. [Beitr. Tabakforsch. Int. 21 (2004) 184-191] 
Table 1. Conditions for making different moisture levels

\begin{tabular}{|c|c|c|c|}
\hline Cigarettes & Salt used in moisture chamber & $\mathrm{RH}$ in chamber (\%) ${ }^{\mathrm{a}}$ & Measured moisture in cigarette \\
\hline Cigarette D (dry) & $\mathrm{MgCl}_{2}$ & 32.9 & 7.8 \\
\hline Cigarette R (regular) & $\mathrm{K}_{3} \mathrm{C}_{6} \mathrm{H}_{5} \mathrm{O}_{7}$ & 62.5 & 14.5 \\
\hline Cigarette M (moist) & $\mathrm{NaCl}$ & 75.3 & 20.4 \\
\hline
\end{tabular}

${ }^{\text {a }}$ Calculated at $25^{\circ} \mathrm{C}$

\section{INTRODUCTION}

It is common knowledge that the same cigarette tastes differently for different moisture contents. Dry cigarettes are more irritating than regular cigarettes. Moisture content, as one of the physical variables of cigarettes affects the level of total particulate matter (TPM) (1-3), although the dry smoke condensate reported to the dry weight of tobacco is not much modified. A number of other reports on the influence of moisture content on smoke, besides changes in TPM, indicated changes in the amount of tobacco burned during smoldering, changes in nicotine, phenol, menthol (4-9), as well as changes in the smoke quality $(6,10)$. Also, the effect of cigarette moisture on the composition of each puff has been studied for a few individual components $(6,7)$. Some other studies were focused on the influence of filtration at different moistures. In one such study (8) it was concluded that the filtration coefficient of the tobacco rod is dependent on the moisture content of tobacco, high moisture resulting in higher filtration. Another study (9) concluded that lower tobacco moisture did not affect the filtration of the tobacco rod, but reduced the rate of direct condensation and aerosol formation. These two reports evaluated one component (phenol), 'tar' (as TPM minus water and nicotine) and nicotine only, and did not take into account that different components may behave differently in particulate phase smoke under the influence of moisture content. Valuable information on the differences between dry and moist cigarettes were obtained from some of these studies. For example, in one study (10), $30 \mathrm{~mm}$ sections from the burning end of dry cigarettes and from moist cigarettes were cut and exchanged. During smoking, some harshness typical for dry cigarettes was still noticed for moist cigarettes with a dry mouth end, but an overwhelming difference was noticed for dry tobacco sections with a moist mouth end. This clearly indicated the role of tobacco moisture in modifying the pyrolytic process during smoking. Also, the same study (10) showed the importance of the first few puffs in determining sensory differences between dry and moist cigarettes. It suggested that the first few puffs of smoke may be significantly affected by the moisture content. Also, the particulate phase smoke of the first few puffs may have changes in the chemical composition for cigarettes with different moisture content. Limited information in previous studies was given about the changes in the relative abundance of a larger number of smoke components in particulate phase smoke under the influence of moisture content. The information on changes of the chemical composition of smoke condensate would provide a better understanding of the sensory changes noticed between dry and moist cigarettes. Even if changes were noted for a particular compound between dry and moist cigarettes, it is not likely that these changes can modify the smoke quality for every cigarette. At the same time, smoke with a modified overall composition will certainly have different sensorial properties.

The present study was conducted to evaluate the importance of moisture content on the chemical composition of particulate phase smoke of cigarettes, and the experiments were performed for the whole cigarette as well as for the first three puffs of the cigarette. The reason for collecting and studying only the first three puffs of smoke was that the moisture content in the tobacco column changes during the smoking process. The condensation of water in the tobacco column behind the burning end, will increase the moisture content even for a dry cigarette, and the potential differences in the composition of particulate phase smoke can be significantly reduced by the water accumulated in the cigarette column during smoking. Thus, the true influence of cigarette moisture cannot be properly evaluated.

\section{EXPERIMENTAL}

\section{Cigarette condition}

The achievement of a different moisture content in cigarettes was done by conditioning cigarettes in moisture chambers with different relative humidities $(\mathrm{RH})$. Three saturated solutions of selected salts were placed separately in three moisture chambers. Cigarettes were then placed in the moisture chamber for at least seven days to obtain the desired moisture content, indicated as Cigarette D for dry, Cigarette $\mathrm{R}$ for regular, and Cigarette $\mathrm{M}$ for moist. The salts used for obtaining the desired moisture were selected based on literature recommendations $(11,12)$. The measurement of moisture was done using only the cigarette tobacco, by a routine oven moisture measurement (13). The obtained moisture contents of the three cigarettes are listed in Table 1 .

\section{Cigarette smoking}

The cigarette smoking for all three cigarettes was done under standard Federal Trade Commission (FTC) smoking procedure (14) and was performed on a Borgwaldt RM 20/CS rotary smoking machine. Cigarettes were smoked for a puff of $35 \mathrm{~mL}$ with $2 \mathrm{~s}$ duration in every $60 \mathrm{~s}$. Two sets of experiments were conducted, one in which the whole cigarette was smoked and the TPM collected, and the other where only the first three puffs of each cigarette were collected. 
Table 2. Routine smoke results of entire cigarettes

\begin{tabular}{lcc|c|c|c}
\hline Cigarettes & Puff number & TPM (mg/cig) & 'Tar' (mg/cig) & Water (mg/cig) & Nicotine (mg/cig) \\
\hline Cigarette D (dry) & 6.9 & 20.21 & 17.47 & 1.67 & 1.07 \\
Cigarette R (regular) & 7.7 & 19.59 & 16.51 & 2.27 & 0.81 \\
Cigarette M (moist) & 8.5 & 19.33 & 16.14 & 2.50 & 0.69 \\
\hline
\end{tabular}

Table 3. Routine smoke results of the first three puffs (based on 3-puffs smoke)

\begin{tabular}{lcc|c|c}
\hline Cigarettes & TPM (mg/cig) & 'Tar' (mg/cig) & Water $(\mathrm{mg} / \mathrm{cig})$ & Nicotine $(\mathrm{mg} / \mathrm{cig})$ \\
\hline Cigarette D & 7.13 & 6.06 & 0.66 & 0.41 \\
Cigarette R & 5.81 & 4.65 & 0.88 & 0.27 \\
Cigarette M & 5.02 & 3.73 & 1.08 & 0.21 \\
\hline
\end{tabular}

\section{Sample collection}

For entire cigarette smoke experiments, 10 cigarettes were smoked to $3 \mathrm{~mm}$ from the tipping paper. The particulate phase smoke was collected on a conditioned $44 \mathrm{~mm}$ Cambridge pad. The pad was weighed before and after smoking to obtain the TPM value. The smoke pad was kept in a flask containing $10 \mathrm{~mL}$ of extracting solution. The extracting solution was $t$-butyl methyl ether (TBME) with $20 \mu \mathrm{g} / \mathrm{mL} 2$-methylnaphthalene. After being mechanically shaken for $30 \mathrm{~min}$, a portion of the extract solution was placed into a $1.7 \mathrm{~mL}$ autosampler vial for gas chromatography-mass spectrometry (GC-MS) analysis.

For the first 3-puffs experiment, 10 cigarettes were smoked only for the first three puffs. The particulate-phase smoke of three consecutive runs (total 90 puffs) was collected. This approach was used to obtain TPM values close to that of the entire cigarette smoke experiment, and to avoid the possible chromatographic artifacts due to significantly different TPM values.

\section{GC-MS analysis}

The GC-MS analysis of the smoke pad was reported previously (15). The compounds measured in this study, cover a range of common smoke constituents. The instrument used for this study was a VG AutoSpec GC/HR-MS system with the separation done on a DB-5MS capillary column $(60 \mathrm{~m} \times 0.25 \mathrm{~mm}, 0.5 \mu \mathrm{m}$ film thickness $)$. The GC oven was programmed at an initial temperature of $36^{\circ} \mathrm{C}$ for 3 min, a heating rate of $1{ }^{\circ} \mathrm{C} / \mathrm{min}$ to $60{ }^{\circ} \mathrm{C}$, then a heating rate of $2{ }^{\circ} \mathrm{C} / \mathrm{min}$ to $310{ }^{\circ} \mathrm{C}$, and final time of $30 \mathrm{~min}$. The injector and ion source temperatures were both at $250{ }^{\circ} \mathrm{C}$. Splitless injection of $0.5 \mu \mathrm{L}$ sample was used with a purge off time of $0.5 \mathrm{~min}$. The mass spectrometer was operated in the scan mode with a range of $\mathrm{m} / \mathrm{z} 40$ to $\mathrm{m} / \mathrm{z} 400$. The voltage applied to the detector was 280 volts (normally 200-240 volts) for maximum sensitivity. All samples were run in duplicate.

The compounds were identified using mass spectral library searches only. The levels of selected compounds in particulate phase smoke were estimated by the comparison of the peak area of the compound of interest with that of the internal standard. Each compound area was measured using the extracted ion of the base peak in the mass spectrum in order to avoid interferences. The reported data were the average of duplicates.

\section{RESULTS AND DISCUSSION}

The results for TPM, water, and nicotine (and the 'tar' = TPM - water - nicotine) of the entire cigarette smoke for the cigarette at three moisture levels (D, R and M) are listed in Table 2. There were considerable differences in puff numbers for the three cigarettes. However, the differences in TPM and 'tar' values for the three cigarettes were not very large. The percentage of water in TPM of the three cigarettes for entire cigarette smoke is $8.3 \%, 11.6 \%$ and $12.9 \%$, respectively. Taking Cigarette $\mathrm{R}$ as a standard, the TPM ratios for D/R and $M / R$ are 1.03 and 0.99 , while the 'tar' ratios of $D / R$ and $M / R$ are 1.06 and 0.98 , respectively.

The first 3-puffs experiment showed more differences among the three moisture levels. The results of first 3-puffs smoke are listed in Table 3. The data in Table 3 are reported in $\mathrm{mg} / \mathrm{cig}$ using only 3-puffs smoke per cigarette. There were clear differences in TPM and 'tar' values for the three cigarettes. The percentages of water in TPM for Cigarette D, Cigarette $\mathrm{R}$ and Cigarette $\mathrm{M}$ are $9.3 \%, 15.2 \%$ and $21.5 \%$, respectively, which are close to the cigarette moisture content. The nicotine content was reduced with the increasing of the cigarette moisture. Also taking Cigarette $\mathrm{R}$ as a standard, the TPM ratios for $\mathrm{D} / \mathrm{R}$ and $\mathrm{M} / \mathrm{R}$ are 1.23 and 0.86 , while the 'tar' ratios of $\mathrm{D} / \mathrm{R}$ and $\mathrm{M} / \mathrm{R}$ are 1.30 and 0.80 , respectively. The moisture level significantly affected the TPM values for the first 3-puffs smoke while the change was less obvious for the entire cigarette smoke.

The list of 75 selected compounds analyzed in particulate phase smoke is given in Table 4 . To compare the change in the levels of particulate phase smoke for different moisture contents, the relative ratios of the peak areas for the 75 compounds between Cigarettes $\mathrm{D}$ and $\mathrm{R}$ and between Cigarettes $\mathrm{M}$ and $\mathrm{R}$ were calculated. Figures 1 and 2 show the compound ratios for $\mathrm{D} / \mathrm{R}$ and $\mathrm{M} / \mathrm{R}$, respectively. Particulate phase smoke can be classified into two groups of compounds (16): non-volatile and semi-volatile compounds. The selected 75 compounds were all semi-volatile compounds with different volatilities. As a reference, the 
Table 4. Selected compounds measured in particulate phase smoke

\begin{tabular}{|c|c|c|c|c|}
\hline Number & Compound & CAS No. & MW (nominal) & b.p. ${ }^{\circ} \mathrm{C}^{\mathrm{a}}$ \\
\hline 1 & Pyrazine & $290-37-9$ & 80 & $115-116$ \\
\hline 2 & Pyridine & $110-86-1$ & 79 & 115.2 \\
\hline 3 & 2-Methylpyridine & $109-06-8$ & 93 & $128-129$ \\
\hline 4 & 2-Methylpyrazine & $109-08-0$ & 94 & 135 \\
\hline 5 & Furfural & $98-01-1$ & 96 & 161.8 \\
\hline 6 & 5-Methyl-2(5H)-furanone & $591-11-7$ & 98 & 208-209 \\
\hline 7 & 2-Furanmethanol & $98-00-0$ & 98 & 170 \\
\hline 8 & 3-Ethylpyridine & $108-99-6$ & 93 & $143-144$ \\
\hline 9 & 2-Ethylfuran & $3208-16-0$ & 96 & $92-93$ \\
\hline 10 & 2,6-Dimethylpyridine & $108-48-5$ & 107 & 144 \\
\hline 11 & 2-Ethylpyridine & $100-71-0$ & 107 & 149 \\
\hline 12 & $2(5 H)$-Furanone & $497-23-4$ & 84 & $86-87 / 12 \mathrm{~mm}$ \\
\hline 13 & 1-(2-furanyl)ethanone & $1192-62-7$ & 110 & $67 / 10 \mathrm{~mm}$ \\
\hline 14 & 2,5-Dimethylpyrazine & $123-32-0$ & 108 & 155 \\
\hline 15 & Ethylpyrazine & $13925-00-3$ & 108 & $152-153$ \\
\hline 16 & 2,3-Dimethylpyrazine & $5910-89-4$ & 108 & 156 \\
\hline 17 & 5-Methyl-2(3H)-furanone & $591-12-8$ & 98 & 167 \\
\hline 18 & 2,4-Dimethylpyridine & $108-47-4$ & 107 & 159 \\
\hline 19 & 2,5-Dimethylpyridine & $589-93-5$ & 107 & 157 \\
\hline 20 & 2-Vinylpyridine & $100-69-6$ & 105 & $79-82 / 29$ mm \\
\hline 21 & 3-Ethylpyridine & $536-78-7$ & 107 & 166 \\
\hline 22 & 5-Methylfurfural & $620-02-0$ & 110 & 187 \\
\hline 23 & 3-Vinylpyridine & $1121-55-7$ & 105 & 162.7 \\
\hline 24 & 3,5-Dimethylpyridine & $591-22-0$ & 105 & $169-170$ \\
\hline 25 & Phenol & $108-95-2$ & 94 & 182 \\
\hline 26 & 2-Propylpyridine & $622-39-3$ & 121 & 179 \\
\hline 27 & Trimethylpyrazine & $14667-55-1$ & 122 & $171-172$ \\
\hline 28 & 2-(4-Pyridyl)furan & $55484-04-3$ & 145 & $120 / 13 \mathrm{~mm}$ \\
\hline 29 & $o$-Cresol ${ }^{b}$ & $95-48-7$ & 108 & 191 \\
\hline $29^{\prime}$ & $m$-Cresol ${ }^{b}$ & $108-39-4$ & 108 & 203 \\
\hline 30 & 2,5-Dimethyl-4-hydroxy-3(2H)-furanone & $3658-77-3$ & 130 & m.p. $78-83$ \\
\hline 31 & 2-Acetylpyrrole & $1072-83-9$ & 109 & m.p. $>85$ \\
\hline 32 & 5-Ethyldihydro-2(3H)-furanone & $695-06-7$ & 114 & $96-97 / 10 \mathrm{~mm}$ \\
\hline 33 & $p$-Cresol & $106-44-5$ & 108 & 202 \\
\hline 34 & 3-Methylpyrrolidine-2,5-dione & $1072-87-3$ & 113 & $122-125$ \\
\hline 35 & 4-Hydroxypyridine (4-pyridinol) & $626-64-2$ & 95 & $190-191$ \\
\hline 36 & 2,6-Dimethylphenol & $576-26-1$ & 122 & 203 \\
\hline 37 & 3-Pyridinol acetate & $17747-43-2$ & 137 & $137 / 58 \mathrm{~mm}$ \\
\hline 38 & 5-Methyl-2(1H)-pyridinone & $1003-68-5$ & 109 & $180-187$ \\
\hline 39 & 2,5-Pyrrolidindione (succinimide) & $123-56-8$ & 99 & 287 \\
\hline 40 & 3,5-Dimethylphenol & $108-68-9$ & 122 & m.p. 65-66 \\
\hline 41 & 6-Methyl-2-pyrazinylmethanol & $77164-93-3$ & 124 & m.p. 45 \\
\hline 42 & 2,4-Dimethylphenol & $105-67-9$ & 122 & $211-212$ \\
\hline 43 & 3,4-Dimethylphenol & $95-65-8$ & 122 & m.p. 65-68 \\
\hline 44 & $1,3,5$-Trimethyl- $1 H$-pyrazole & $1072-91-9$ & 110 & m.p. 38-41 \\
\hline 45 & Piperidine-2,6-dione (glutarimide) & $1121-89-7$ & 113 & m.p.155 \\
\hline 46 & 6-Methyl-2-pyridinol & $1121-78-4$ & 109 & m.p.158 \\
\hline 47 & 3,4-Dimethylpyrrolidin-2,5-dione & $17825-86-4$ & 127 & m.p. 118-119 \\
\hline 48 & 3-Ethylphenol & $620-17-7$ & 122 & 215 \\
\hline 49 & Catechol & $120-80-9$ & 110 & 245 \\
\hline 50 & 2,3-Dihydrobenzofuran (coumaran) & $496-16-2$ & 120 & $188-189$ \\
\hline 51 & 5-(Hydroxymethyl) furfural & $67-47-0$ & 126 & m.p. 32-35 \\
\hline 52 & Resorcinol & $108-46-3$ & 110 & m.p.110-112 \\
\hline 53 & 3-Ethyl-4-methylpyrrolidin-2,5-dione & $20189-42-8$ & 141 & m.p. $63-72.5$ \\
\hline 54 & Quinoline & $91-22-5$ & 129 & $113-114 / 17 \mathrm{~mm}$ \\
\hline 55 & Hydroquinone & $123-31-9$ & 110 & 185 \\
\hline 56 & 5-Amino- $1 \mathrm{H}$-indole & 5192-03-0 & 132 & m.p.131-133 \\
\hline 57 & 2-Methylbenzofuran & $17059-52-8$ & 132 & $197-198$ \\
\hline 58 & 3-Methyl-1 $\mathrm{H}$-indole & 83-34-1 & 131 & $265-266$ \\
\hline
\end{tabular}


Table 4 (cont.)

\begin{tabular}{llc|c|c}
\hline Number & Compound & CAS No. & MW (nominal) & b.p. ${ }^{\circ} \mathrm{C}^{\mathrm{a}}$ \\
\hline 59 & 4,7-Dimethylbenzofuran & $28715-26-6$ & 146 & $101-102 / 19 \mathrm{~mm}$ \\
60 & Myosmine & $352-12-7$ & 146 & $\mathrm{~m} . \mathrm{p} .45$ (dec.) \\
61 & 2,3-Dimethylhydroquinone & $608-43-5$ & $\mathrm{~m} . \mathrm{p} .221$ \\
62 & 1,3-Dihydroindol-2-one & $59-48-3$ & 138 & $\mathrm{~m} . \mathrm{p} .127$ \\
63 & Nicotyrine & $487-19-4$ & 133 & 281 \\
64 & 2,3-Dimethyl-1H-indole & $91-55-4$ & 158 & 285 \\
65 & Anabasine & $494-52-0$ & 145 & $96 / 12 \mathrm{~mm}$ \\
66 & 3,5-Dimethyl-1-phenylpyrazole & $1131-16-4$ & 162 & 273 \\
67 & Anatabine & $581-49-7$ & 172 & $145-146$ \\
68 & 2,3'-Bipyridine & $581-50-0$ & 160 & 295.5 \\
69 & 2-Aminonaphthalene & $91-59-8$ & 156 & 306 \\
70 & 5-Quinolineamine & $611-34-7$ & 143 & 310 \\
71 & 4-Aminobiphenyl & $92-67-1$ & 144 & $\mathrm{~m} . \mathrm{p} .52-54$ \\
72 & Cotinine & $486-56-5$ & 169 & $\mathrm{~m} . \mathrm{p} .40-42$ \\
73 & N-fomyl-nornicotine & $3000-81-5$ & 176 & 206 \\
74 & Carbazol & $86-74-8$ & 176 & 355 \\
75 & B-Carboline (norharman) & $244-63-3$ & 167 & $\mathrm{~m} . \mathrm{p} .198$ \\
\hline
\end{tabular}

a The boiling point (b.p.) at $760 \mathrm{~mm} \mathrm{Hg}$ pressure is not available for all compounds. The b.p. for some compounds is reported at a different pressure, and for other compounds only the melting point (m.p.) is reported.

${ }^{\mathrm{b}}$ Not separated in the chromatogram.

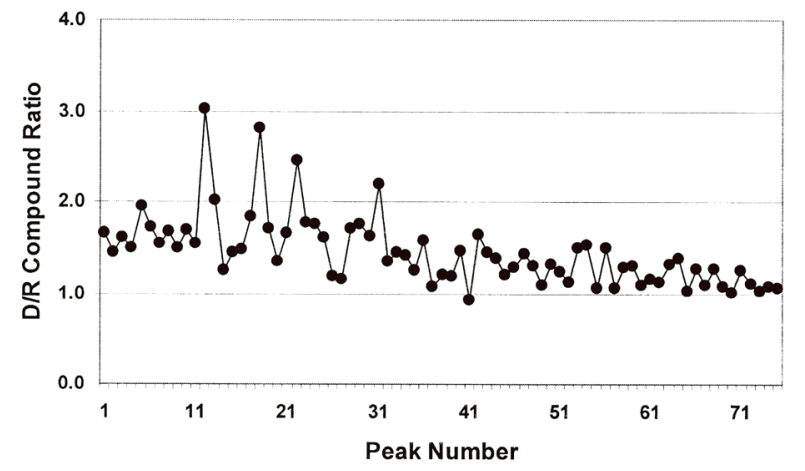

Figure 1. Compound ratios of dry to regular cigarettes for entire cigarette smoke

boiling points (b.p.) or the melting points (m.p) for the analyzed compounds are shown in Table 4 . It can be noticed from Table 4 that the boiling points (or the melting points) have a clear tendency to increase as the peak number in the chromatogram increases. All the analyzed compounds are typically collected in the 'tar' and their content in vapor phase is virtually negligible (17). The D/R ratios for all the 75 compounds in Figure 1 were higher than the D/R TPM ratio of 1.03 . This would suggest that the dry cigarettes had a slightly higher percentage of semivolatile compounds in TPM than regular cigarettes. Figure 1 shows also that the more-volatile compounds (small peak numbers corresponding to lower molecular weight) had higher $\mathrm{D} / \mathrm{R}$ ratios and varied in a wide range. In contrast, the $\mathrm{D} / \mathrm{R}$ ratios for the less-volatile compounds (large peak numbers) were around 1.03 with a relatively small variation.

Figure 2 shows the same behavior. The individual compound $\mathrm{M} / \mathrm{R}$ ratios were slightly below the M/R TPM ratio of 0.97 . Also, the more-volatile compounds had lower M/R ratios than less-volatile compounds.

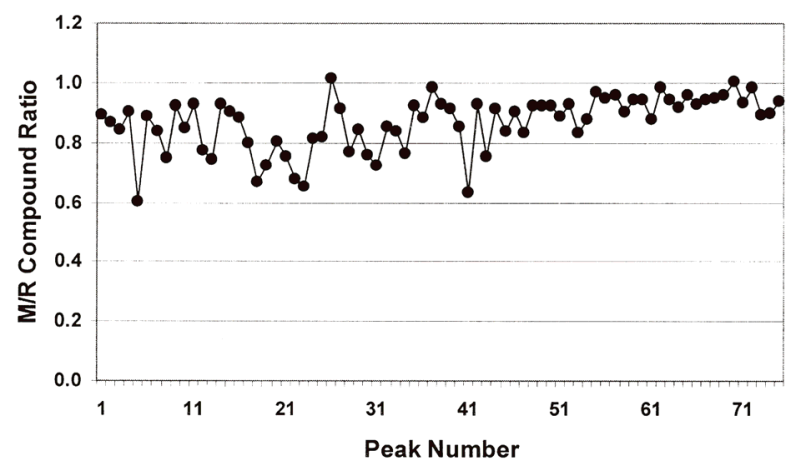

Figure 2. Compound ratios of moist to regular cigarettes for entire cigarette smoke

Figures 1 and 2 demonstrate that for entire cigarette smoke, dry cigarettes generated a higher percentage of compounds, and moist cigarettes generated a lower percentage of compounds than regular cigarettes. Also, the smoke of a dry cigarette is richer in lower molecular mass compounds than a regular cigarette. On the other hand, the smoke of a moist cigarette is richer in higher molecular mass compounds than a regular cigarette.

The next part of the experiment was performed for making the comparison of the results for the first three puffs of the $\mathrm{R}, \mathrm{D}$ and $\mathrm{M}$ cigarettes. In a similar manner to the whole cigarette experiment, D and $\mathrm{M}$ cigarettes had respectively the highest and the lowest levels of those 75 compounds, but the differences in the levels of the selected 75 compounds among the three cigarettes for the first 3-puffs experiment were significantly larger than those for entire cigarette smoke.

The D/R ratios for all the 75 compounds in Figure 3 were significantly higher than the D/R TPM ratio that was 1.23. This suggests that the first 3-puffs smoke of dry cigarettes had a significantly higher percentage of semi-volatile 


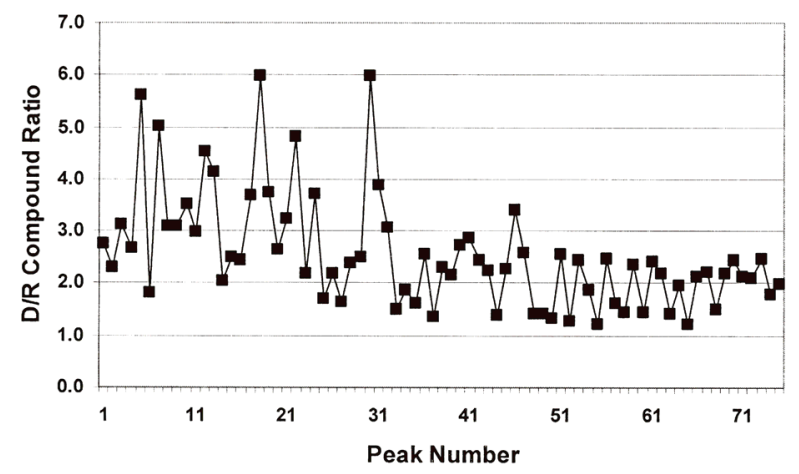

Figure 3. Compound ratios of dry to regular cigarettes for the 3-puffs experiment

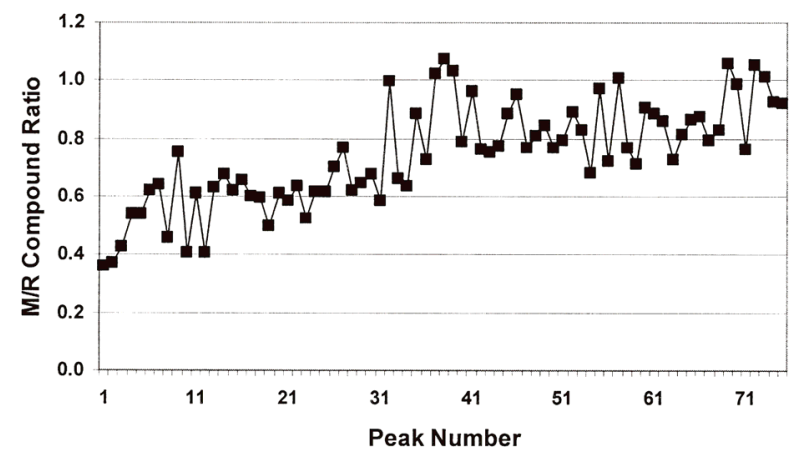

Figure 4. Compound ratios of moist to regular cigarettes for the 3-puffs experiment

compounds in TPM than regular cigarettes. Figure 3 shows also that the more-volatile compounds (small peak numbers) had higher $\mathrm{D} / \mathrm{R}$ ratios and varied in a wide range. In contrast, the $\mathrm{D} / \mathrm{R}$ ratios for the less-volatile compounds (large peak numbers) were around 2.0 with a relatively small variation.

The M/R ratios for the 75 compounds in Figure 4 showed that the moist cigarettes had a lower percentage of semivolatile compounds in TPM than the regular cigarettes. The $\mathrm{M} / \mathrm{R}$ ratios for the more-volatile compounds were lower than the M/R TPM ratio of 0.86 , while $M / R$ ratios for the less-volatile compounds were about 0.86 .

Compared to entire cigarette smoke, the particulate phase smoke of the first three puffs had a significantly larger difference in $\mathrm{D} / \mathrm{R}$ and $\mathrm{M} / \mathrm{R}$ ratios. The balance of particulate phase smoke was significantly altered for the first three puffs when moisture content changed.

From the data shown in Figures 1 to 4, it can be concluded that the moisture content in cigarettes significantly affects the chemistry of particulate phase smoke. The behavior can be summarized as: 1) Dry cigarettes had a higher percentage of semi-volatile compounds in TPM, while moist cigarettes had a lower percentage of semi-volatile compounds in TPM, than regular cigarettes. 2) The abundance of the more-volatile compounds in TPM were significantly affected by cigarette moisture, while the less-volatile compounds were affected in a reduced degree.

To further compare the differences in particulate phase smoke between the 3-puffs experiment and entire cigarette smoke, the relative ratios of the 75 selected compounds in TPM collected from three puffs and entire cigarettes was

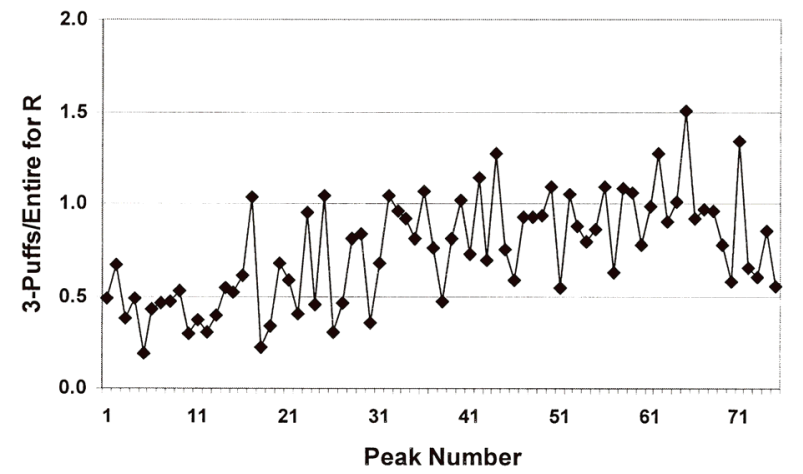

Figure 5. Normalized compound ratio of the 3-puffs experiment to entire cigarette smoke for regular cigarettes

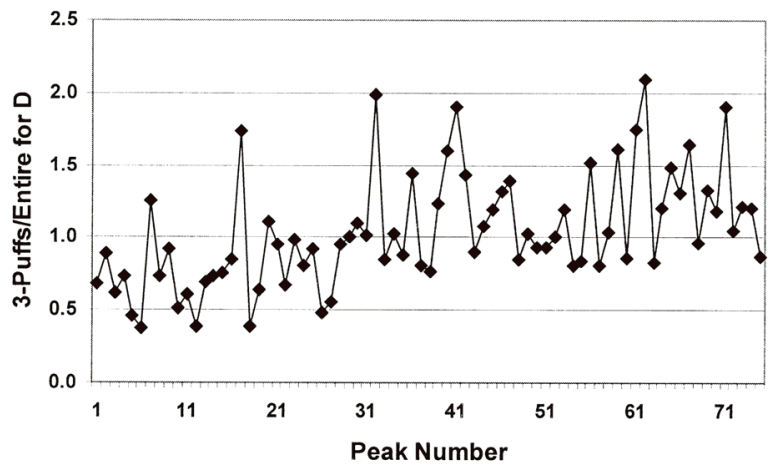

Figure 6. Normalized compound ratio of the 3-puffs experiment to entire cigarette smoke for dry cigarettes

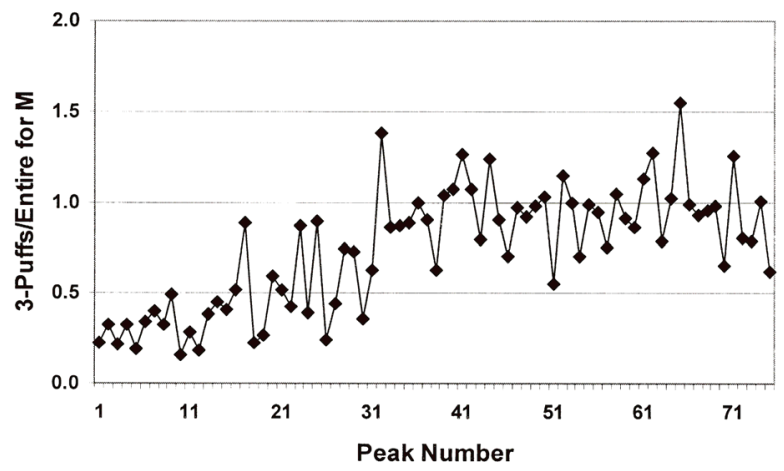

Figure 7. Normalized compound ratio of the 3-puffs experiment to entire cigarette smoke for moist cigarettes

obtained. Figures 5 to 7 show the comparison for D, R, and $\mathrm{M}$ cigarettes, respectively. The normalized value of an individual compound was obtained by comparing its abundance to the corresponding TPM value. The 3puffs/entire ratio for an individual compound was then obtained by comparing the normalized values of the 3 -puffs experiment to entire cigarette smoke.

Figure 5 shows the normalized 3-puffs/entire ratios of the 75 selected compounds for $\mathrm{R}$ cigarettes. The ratios for the more-volatile compounds were below 1.0 while the lessvolatile compounds were about 1.0. If first 3-puffs smoke and entire cigarette smoke generated the same levels of these compounds in TPM, the ratios should be constant at 1.0. This would suggest that for the regular cigarettes, the first few puffs generated a lower percentage of more- 
volatile compounds in TPM than entire cigarette smoke, while the percentage of the less-volatile compounds in TPM was almost the same for the first few puffs and entire cigarette smoke.

Dry and moist cigarettes showed a different behavior. The 3 -puffs/entire ratios for the more-volatile compounds in Figure 6 (Cigarette D) were close to 1.0, while the ratios for the less-volatile compounds were significantly higher than 1.0. The 3-puffs/entire ratios for the more-volatile compounds in Figure 7 (Cigarette $\mathrm{M}$ ) were significantly below 1.0 .

Overall, the first 3-puffs experiment and entire cigarette smoke showed a different chemical composition of particulate phase smoke. The first three puffs generated a lower percentage of the more-volatile compounds in TPM than the entire cigarette smoke, especially for moist cigarettes, and the dry cigarettes generated a higher percentage of the less-volatile compounds in TPM than entire cigarette smoke.

Several causes may generate the differences seen in the chemical composition between the smoke condensate of $\mathrm{D}$, $\mathrm{R}$ and $\mathrm{M}$ cigarettes. These may include the differences in the burn rate during the puff and during smoldering, filtration through the tobacco rod, filtration through the filter, and pyrolysis [see also (6)]. The findings from other studies (6) in the levels of phenol, nicotine, and menthol for dry and moist cigarettes suggested that the main cause is the difference in the retention of smoke constituents by the tobacco rods of moist and dry cigarettes. The present study shows a clear correlation between the volatility of the compounds from smoke and their levels in the TPM of dry and moist cigarettes. No difference in the burn rate during puffing is reported in the literature (6) and the differences in the smoldering rate should affect equally the level of compounds with low or high volatility. Although no specific experiment was conducted to verify the role of filtration in a moist tobacco column vs. a dry one, it is known that filtration of particulate matter is mainly a mechanical process (16). Also, a moist and more polar tobacco column would be more likely to retain the more polar compounds that are not volatile, and the moist cigarette should easily release the more volatile compounds. The observation from the present study is just the opposite, the moist tobacco generates TPM which is richer in higher molecular mass compounds. This does not exclude the role of moisture differences on direct condensation and aerosol formation (9), but indicates that changes in pyrolysis are the most likely cause in the differences in the TPM composition of moist vs. dry cigarettes.

\section{CONCLUSION}

The moisture content of cigarettes influenced the chemical composition of particulate phase smoke. The percentages of individual compounds in TPM were different for the cigarettes with different moisture levels. Dry cigarettes had the highest percentages of semi-volatile compounds in TPM while moist cigarettes had the lowest. Among the selected 75 compounds, the more-volatile compounds would be more affected than the less-volatile compounds. Compared to the first 3-puffs experiment, the particulate phase smoke of entire cigarette smoke was less sensitive to the moisture content. The cigarette moisture significantly affects the particulate phase smoke for the first few puffs. The effect of moisture on the pyrolytic process is considered the likely cause of the differences seen in the TPM composition between the dry and moist cigarettes.

\section{REFERENCES}

1. Rayburn, C.H.: Tobacco smoke: Influence of certain variables on the composition of cigarette smoke; $4^{\text {th }}$ TCRC Conference, State College PA, 1950.

2. Newsome, J.R. and C.H. Keith: The effect of physical variables on the weight of smoke produced by a burning cigarette; $10^{\text {th }}$ TCRC Conference, Washington DC, 1956.

3. Debardeleben, M.Z., W.E. Claflin, and W.F. Gannon: Role of cigarette physical characteristics on smoke composition; $32^{\text {nd }}$ TCRC Conference, Montreal Canada, 1978.

4. Neurath, G. and H. Horstmann: Effect of moisture content of cigarettes on the composition of smoke and temperature in the combusting zone; Beitr. Tabakforsch. 2 (1963) 93-100.

5. Ehmke, H. and G. Neurath: Effect of moisture content of cigarettes on the composition of smoke II; Beitr. Tabakforsch. 2 (1964) 205-208.

6. Green C.R., F.W. Conrad Jr., M.F. Dube, J.L. Harris, and A.L. Angel: Dry cigarette chemistry; RJR report, 1982, No. 5, April 2, see http://www.rjrtdocs.com.

7. Seehofer, E., D. Hanssen, and R. Schroeder: Individual puff analysis of smoke; Beitr. Tabakforsch, 3 (1965) 135-150.

8. Esterle, J.G. and A.R. Campbell: The Effect of moisture on tobacco on phenol filtration and delivery; $18^{\text {th }}$ TCRC Conference, Raleigh NC, 1964.

9. Townsend, D.E.: The effect of tobacco moisture on the removal of cigarette smoke by the tobacco rod; $37^{\text {th }}$ TCRC Conference, Washington DC, 1983.

10. Rudolph, G. and F.K. St.Charles: Why are dry cigarettes more irritating?; B\&W internal correspondence, May 16, 1986, http://www.bwdocs.com.

11. Greenspan, N.: Humidity fixed points of binary aturated solutions, J. Res. Natl. Bur. Stand. Sect. A, 81A Jan-Feb. 1977, pp 89-96.

12. Daum, J.F.X.: Measurement of the relative humidity of potassium citrate solutions; B\&W file note, Nov. 8, 1987, http://www.bwdocs.com.

13. Gregory C. and O. Lin: Oven moisture of cut cigarette tobacco; B\&W lab. protocol, Sept. 24, 1990 http://www.bwdocs.com.

14. Pillsbury, H.C., C.C. Bright, K.J. O'Connor, and F.H. Irish: Tar and nicotine in cigarette smoke; JAOAC 52 (1969) 458-462.

15. Moldoveanu, S.C.: Analytical pyrolysis of natural organic polymers; Elsevier, Amsterdam, 1998, pp. 450-455. 
16. Browne, C.L.: The design of cigarettes; Hoechst Celanese Corporation; Charlotte, NC, $3^{\text {rd }}$ Ed., 1990, p. 72.

17. Dong, J.-Z., H.J. Glass, and S.C. Moldoveanu: A simple GC-MS technique for the analysis of vapor phase mainstream cigarette smoke; J. Microcol. Sep. 12 (2000) 142-152.
Address for correspondence:

Serban C. Moldoveanu

R.J. Reynolds Tobacco Company

950 Reynolds Boulevard, Winston-Salem, NC 27105

USA

e-mail: SMoldov@aol.com 